\title{
Future of Neurology \& Technology: Virtual and Augmented Reality in Neurology and Neuroscience Education
}

\author{
Applications and Curricular Strategies
}

Stefano Sandrone, PhD, and Chad E. Carlson, MD

Neurology ${ }^{\circledR}$ 2021;97:740-744. doi:10.1212/WNL.0000000000012413
Correspondence

Dr. Sandrone

sandrone.stefano@

gmail.com

\begin{abstract}
Virtual reality and augmented reality have become increasingly prevalent in our lives. They are changing the way we see and interact with the world and have started percolating through medical education. In this article, we reviewed the key applications of virtual and augmented realities in neurology and neuroscience education and discussed barriers and opportunities for implementation in the curriculum. Although the long-term benefits of these approaches over more traditional learning methods and the optimal curricular balance remain mostly unexplored, virtual and augmented reality can change how we teach neurology and neuroscience.
\end{abstract}

\section{Introduction}

Virtual reality (VR) and augmented reality (AR) are changing the way we see and interact with the world and hold great potential for the future of education. Although often used interchangeably, these expressions refer to distinct approaches to enhance user experiences. VR simulates a real environment and permits the presentation and the control of stimuli within a multisensory, 3D dynamic environment while recording quantifiable responses. ${ }^{1}$ Within an educational context, it provides an environment that is as similar as possible to a real-life scenario. ${ }^{2}$ Instead, AR uses a view of the real world enhanced by overlaying and superimposing computer-generated information, including text, videos, or sounds, on the actual environment. ${ }^{2}$ The development of mobile technologies have made AR possible via mobile devices $^{3}$ and expanded the realm of potential applications to neurology education. In this article, the key applications of VR and AR in neurology and neuroscience education, including neuroanatomy and histology—and potential clinical applications-are reviewed. Opportunities and potential barriers to widespread implementation are discussed.

\section{The Virtual Classroom}

In this section, specific ways in which topics traditionally taught via didactics in the classroom can be transformed with VR/AR technology will be explored.

\section{From Cadaveric Dissections to Computers}

During the past 2 decades, VR and AR tools have been used to teach basic and advanced neuroanatomy to enhance, or replace, traditional cadaveric dissection. A recent review of studies using different methods to teach neuroanatomy showed that nearly half of these already takes advantage of $3 \mathrm{D}$ teaching tools or $\mathrm{AR}^{3}{ }^{3} \mathrm{~A}$ crossover design study was performed to assess the potential benefits of cadaveric vs 3D computer-based learning of neuroanatomy. Forty-seven undergraduate medical education students completed an anatomy knowledge and spatial ability test before being assigned to either a 3D 
neuroanatomy e-learning module or a gross anatomy laboratory featuring cadaveric dissection. ${ }^{4}$ Then, they completed a post-test and were crossed over to the other learning modality before taking a final post-test. ${ }^{4}$ Students assigned to the $3 \mathrm{D}$ neuroanatomy module performed better on the post-test (an absolute difference in mean scores of nearly $12 \%)$. After crossover, both groups performed similarly, but transitioning from the cadaveric anatomy module to the $3 \mathrm{D}$ learning module resulted in a significant increase in test scores. 4

\section{Immersive VR Neuroanatomy Training}

The impact of an immersive VR neuroanatomy training, as opposed to a neuroanatomy textbook, was assessed via a randomized controlled study featuring 64 first- and secondyear medical students. ${ }^{5}$ Virtual material was created in Blender with T1-weighted anatomic magnetic resonance images and tract maps. ${ }^{5}$ Pre- and post-tests were designed with 13 questions assessing the material presented in the module and 9 questions on general neuroanatomic knowledge (not included in the modules), along with a 44question test, given 1 week after the sessions. ${ }^{5}$ A significantly higher number of students felt VR should be used in classrooms compared with the paper-based system (94\% vs $33 \%$ ) and felt less afraid of neuroanatomy after VR (81\% vs $12 \%)$. The VR group did better than the paper-based group regarding the questions focused on the presented material. ${ }^{5}$ Although this report suggests that integration of VR into training has the potential to increase study motivation and decrease neurophobia, as indicated by the results of the satisfaction survey, the follow-up period was brief and the number of questions to assess knowledge retention was probably too small. ${ }^{5}$

Another study divided 84 students into 3 groups. ${ }^{6}$ All groups attended a lecture, with 1 group having only traditional 2D images presented in a single view, the second group having access to VR 3D images shown in the lecture (with which they can interact), and the third group having the same interactive $3 \mathrm{D}$ images presented stereoscopically. The postclass assessments focused on naming the structures of the limbic system, followed by a practical examination requiring them to recognize the same structures on anatomic specimens. ${ }^{6}$ No difference was observed between the stereoscopic vs traditional 3D VR groups, yet these 2 groups performed better on both the knowledge assessment and the practical anatomy assessment. ${ }^{6}$ Although these studies are limited to 3 institutions and had no assessments of long-term retention (e.g., 1 year or beyond), they demonstrate that VR-based learning of neuroanatomy is at least noninferior, and potentially superior, to traditional learning methods of cadaveric anatomy and paper-based materials.

\section{AR Neuroanatomy With a Smartphone}

AR neuroanatomy teaching was assessed with 70 students who participated in 2 lectures on basic, relevant concepts of the ascending and descending tracts of the medulla with $2 \mathrm{D}$ materials. ${ }^{7}$
The control group studied on a book, whereas the experimental group used the same book as a MagicBook with tagged elements which, when viewed with a smartphone, permitted further interaction and visualization. ${ }^{7}$ The group studying with AR materials performed better on the knowledge assessment, and students felt that using the mobile AR application facilitated (79\%), or partially facilitated (21\%), their learning; 3 students of 4 felt it helped decrease their cognitive load, and 1 of 4 thought it partially decreased their cognitive load. ${ }^{7}$

\section{VR Wearables to Manipulate Neurons}

An even more immersive experience was piloted using wearable VR technology and layered images allowing the virtual manipulation of a neuron. This was possible thanks to a prototype favoring real-time interactions with high-resolution cellular modules. ${ }^{8}$ GLASS $($ C technology wearables permitted a user-centric educational experience, which can be flexibly applied to histologic and anatomical contexts, individually or in simultaneous, real-time group. ${ }^{8}$ This approach can be more useful with experienced learners, with certain visuospatial abilities and more complex anatomical aspects. A randomized trial of e-learning instructional design demonstrated that multiple views of a neuroanatomical element might impede learning, particularly for those with relatively low spatial ability; high degrees of control to the students can reduce the effectiveness of learning. ${ }^{9}$

In conclusion, $\mathrm{VR}$ and $\mathrm{AR}$ allow learners to go beyond the limitations imposed by $2 \mathrm{D}$, noninteractive images and create a training environment where visualization and manipulation are possible. ${ }^{2}$ However, future research will have to investigate personalized learning approaches capable of maximizing individual learning experience.

\section{The Virtual Patient}

VR/AR applications also encompass standardized simulations offering immersive experiences focused on decisionmaking and clinical reasoning. The virtual patient is a computer program simulating real-life clinical scenarios. Students can conduct the patient's anamnesis, physical examinations, and define the diagnostic and the therapy, thus developing a series of cognitive clinical skills. ${ }^{10}$ A combined systematic review and meta-analysis in health professionals' education showed that the use of virtual patients was associated with positive effects compared with no educational intervention. ${ }^{10}$ However, many studies were lacking key methodologic details, and less than half have been randomized. ${ }^{10}$ Hence, a focus on rigorous study design methodology might allow better comparability among different works. It is difficult to ascertain whether the virtual patients improved the learning process because of the more standardized experience offered or because of the overall increased patient exposure. Therefore, future educational studies will have to clarify this aspect and create more varied clinical presentations. 


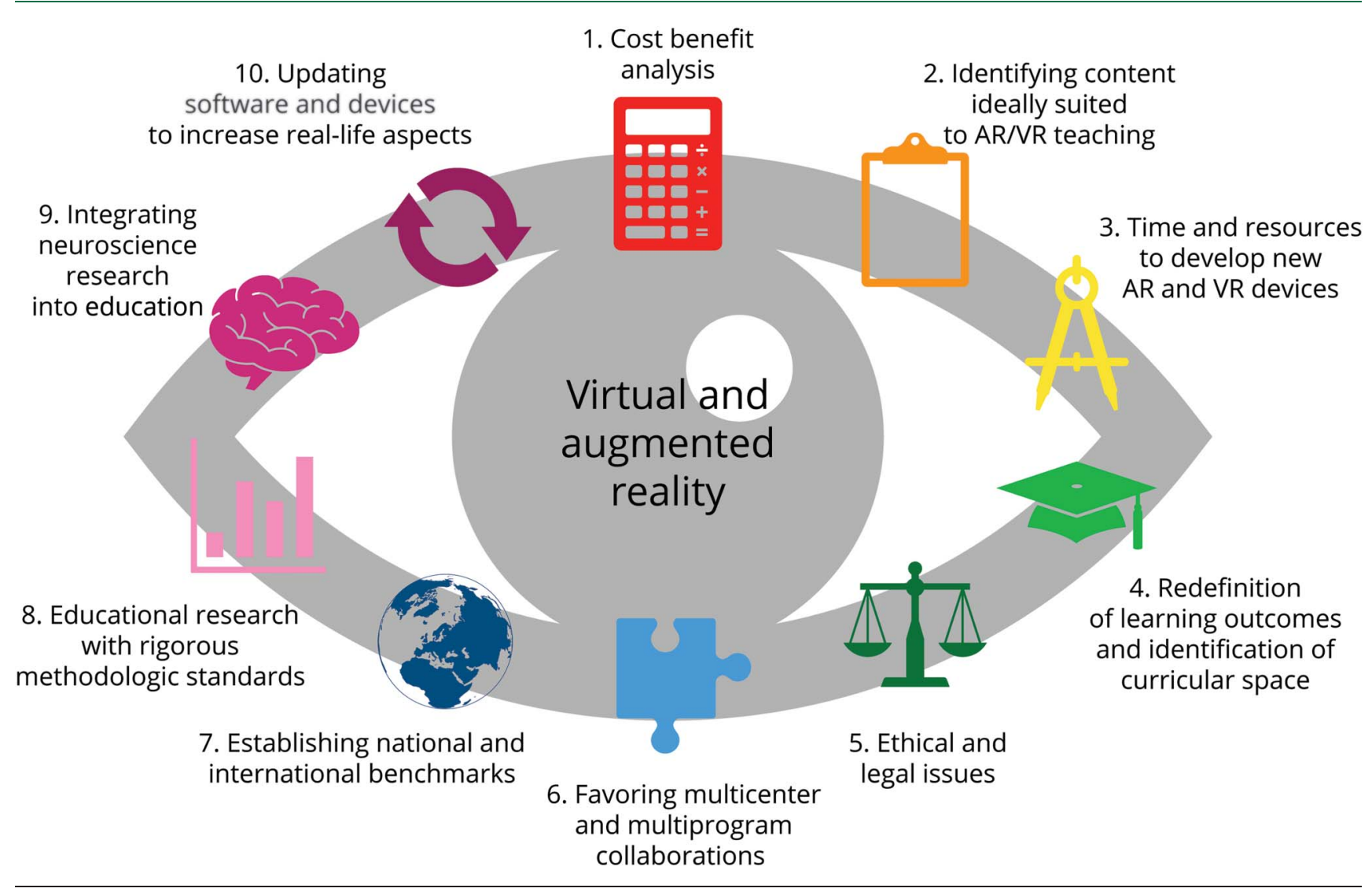

\section{Simulating the Patient Experience}

Virtual technology permits experiencing symptoms and medical conditions, which can help medical providers understand specific pathologies. A VR device was developed to simulate Parkinson disease psychosis combining Oculus Rift technology with the input of patients, caregivers, and healthcare providers. ${ }^{11}$ More than 500 viewers experienced 2 hallucinatory scenarios during 2 international meetings. Motion sickness, which can be a negative consequence of this approach, was rarely reported. The VR scenarios were rated as "likely/very likely" as effective teaching tools for HCP (87.5\%) and caregivers (90.8). One respondent of 2 would even "likely/very likely" change their medical practice. ${ }^{11}$

Building on previous work designed to provide a virtual simulation of hallucinations in the setting of schizophrenia, patient descriptions of auditory and visual hallucinations have been displayed in a virtual environment. ${ }^{12}$ Using the virtual world system of Second Life (Linden Lab, San Francisco, CA), an inpatient psychiatric unit has been created to virtually experience hallucinations. ${ }^{12}$ For 2 months, 579 users took the self-guided tour before completing a survey. ${ }^{12}$ The experience improved the understanding of visual hallucinations (for 69\% of users) of auditory hallucinations (for more than 3 people of 4). ${ }^{12}$ Disease simulation can be applied to other neurologic and psychiatry diseases: a VR simulation of a specific symptom can be paired with a video providing instruction to assess and treat the condition itself and coupled with a test.

\section{The Virtual Operative Assistant}

Simulation-based education (through VR and, to a lesser extent, AR) is another growing trend in neuroscience and neurology education. VR and AR can increase the efficiency of training and treatment delivery and improve patient outcomes by mitigating patient risk, decreasing the chances of error within a zero-risk training environment, and can be used to learn patient-specific anatomy. ${ }^{13}$ Over the past 10 years, it has become increasingly prevalent in procedural fields, including neurosurgery, namely, skull base surgery, stereotactic and functional neurosurgery, vascular surgery, tumor resection, trauma, hydrocephalus, ${ }^{13}$ and spinal neurosurgery. Promising data have also been obtained with VR simulators for neuroendovascular intervention and training of lumbar puncture.

VR has also been coupled with artificial intelligence (AI) to develop the "Virtual Operative Assistant." ${ }^{14}$ This automated educational feedback platform was piloted in 50 among neurosurgeons, fellows, residents, and students, divided into skilled and novice groups to use the VR simulator to perform a subpial brain tumor resection task. ${ }^{14}$ The Virtual Operative Assistant correctly classified skilled and novice participants using 4 metrics with $92 \%$ accuracy. ${ }^{14}$ 
Overall, it showed the feasibility of a new educational paradigm based on objective feedback based on proficiency benchmarks, expertise classification, and instructor input. ${ }^{14}$

\section{Future Developments and Curricular Strategies}

The aim of reaching a fully immersive, dynamic multisensory fusion of virtual and real information, ${ }^{2}$ which can provide a useful platform for real-time navigation for educational and training purposes, remains elusive. As demonstrated from the examples discussed above, using VR/AR technologies can bring advantages, also in increased confidence levels and procedural competency, while offering a safe training environment. There are barriers to overcome, but the steps here described can mitigate them and facilitate the implementation of VR/AR (figure).

The first step is an accurate cost-benefit analysis for the development and usability of these devices. Costs can vary dramatically based on the technology used. These figures are rarely mentioned in peer-reviewed publications, and very few reports have evaluated the feasibility of implementing VR/AR elements within the curriculum. ${ }^{13}$ The lack of a robust financial model or, at least, of a framework increases the difficulty of evaluating feasibility and sustainability of technological devices across educational settings, particularly the under-resourced ones. On the one side, VR/ AR technologies might provide access to educational opportunities that otherwise might not be available to specific groups of learners, hence addressing gaps in medical education. On the other side, although collaborations with industry or startups (and renting, instead of buying, equipment) might mitigate the cost, ${ }^{13}$ money for device maintenance or software updates, i.e., to increase real-life aspects further and improve the immersivity and interactivity, must be budgeted and represents another barrier.

An additional challenge is linked to identifying contents to be used with VR or AR and proper curricular space. Not all educational opportunities might be equally suited for $V R / A R$, and foundational aspects, more than the advanced ones, had a more widespread adoption so far. To ensure that the identified VR/AR solution factually addresses the needed gaps in the curriculum, it is necessary to re-evaluate and realign the learning objectives within the context of the VR/AR training module. Besides the timing of the curricular adoption, the modality of the implementation (i.e., as a standalone module vs integration into a multimodal educational unit ${ }^{2}$ ) must be pondered.

Beyond financial resources, VR and AR typically require an investment in human resources and expertise. Cognitive biases, such as the reluctance of some educators to change the educational status quo, can slow the adoption rate of such technologies. Increasing awareness of the potential benefits of VR/AR can help in this case. Moreover, a lack of local expertise can be compensated by national and international collaborations: sharing resources can fast forward new tools to be used across medical education. In an educational perspective, national and international collaborative efforts might lead to a better standardization of experimental methods and outcomes assessment. This, in turn, will potentially provide the playing field for educational alignment and the creation of new educational benchmarks, in collaboration with societies and relevant stakeholders.

Although computer-based training enhanced the educational landscape, new technological devices have raised novel ethical and legal questions. AI's intrinsic limitations, transparency over data collection methods, and data ownership need to be carefully considered. With VR, besides personal data about location, search queries, and verbal communications, nonverbal behavior such as eye movements, facial expressions, and posture are collected: 20 minutes of VR simulation leads to 2 million unique recordings of body language. ${ }^{15}$ Although these datasets may provide significant scholarly opportunities, they open up considerable privacy concerns for participants. When implementing VR/AR tools for teaching or educational research purposes, considerations of data storage and data protection should be in order.

\section{Conclusions}

VR and AR applications have already altered the educational landscape and constitute promising approaches in medical education. These tools have made their way into neuroscience and neurologic education, in particular neuroanatomy. Simulations of patient experiences in disease states and surgical simulators have become available, although potential barriers, including cost and the necessary expertise to use these tools, persist. As VR and AR become more prevalent, medical educators need to identify ways to adapt curricula to incorporate these teaching tools. Looking forward, collaboration across multiple centers to assess their longterm value remains a crucial opportunity for educational research into $\mathrm{VR} / \mathrm{AR}$.

\section{Study Funding}

The authors report no targeted funding.

\section{Disclosure}

S. Sandrone receives royalties from the Oxford University Press (USA). C.E. Carlson has served as a consultant with Greenwich Biosciences. Dr C Carlson does not receive personal direct payment for this role. Go to Neurology.org/N for full disclosures.

\section{Appendix Authors}

\begin{tabular}{lll}
\hline Name & Location & Contribution \\
\hline $\begin{array}{l}\text { Stefano } \\
\text { Sandrone, } \\
\text { PhD }\end{array}$ & $\begin{array}{l}\text { Imperial College } \\
\text { London }\end{array}$ & $\begin{array}{l}\text { Major role in designing and } \\
\text { conceptualizing the article and } \\
\text { drafted, wrote, and revised different } \\
\text { versions of the manuscript for } \\
\text { intellectual content }\end{array}$ \\
\hline $\begin{array}{l}\text { Chad E. } \\
\text { Carlson, } \\
\text { MD }\end{array}$ & $\begin{array}{l}\text { Medical College of } \\
\text { Wisconsin, }\end{array}$ & $\begin{array}{l}\text { Wrote several sections of the } \\
\text { manuscript and revised different } \\
\text { versions of the manuscript for } \\
\text { intellectual content }\end{array}$ \\
\hline
\end{tabular}




\section{References}

1. Rizzo AA, Talbot T. Virtual reality standardized patients for clinical training. The Digital Patient: Advancing Medical Research, Education, and Practice. 2016:257-272.

2. Bernardo A. Virtual reality and simulation in neurosurgical training. World Neurosurg. 2017;106:1015-1029.

3. Sotgiu MA, Mazzarello V, Bandiera P, Madeddu R, Montella A, Moxham B. Neuroanatomy, the Achille's heel of medical students. A systematic analysis of educational strategies for the teaching of neuroanatomy. Anat Sci Educ. 2020; 13(1):107-116

4. Allen LK, Eagleson R, de Ribaupierre S. Evaluation of an online three-dimensional interactive resource for undergraduate neuroanatomy education. Anat Sci Educ. 2016; 9(5):431-439.

5. Ekstrand C, Jamal A, Nguyen R, Kudryk A, Mann J, Mendez I. Immersive and interactive virtual reality to improve learning and retention of neuroanatomy in medical students: a randomized controlled study. CMAJ Open. 2018;6(1):E103.

6. de Faria JW, Teixeira MJ, Júnior LD, Otoch JP, Figueiredo EG. Virtual and stereoscopic anatomy: when virtual reality meets medical education. J Neurosurg. 2016;125(5):1105-1111.

7. Küçük S, Kapakin S, Göktaş Y. Learning anatomy via mobile augmented reality: effects on achievement and cognitive load. Anat Sci Educ. 2016;9(5):411-421.

8. Riddle S, Wasser D, McCarthy M. Touching the human neuron: user-centric augmented reality viewing and interaction of in-vivo cellular confocal laser scanning microscopy (clsm) utilizing high resolution zstack data sets. J Biocommun. 2017; 41(1).

9. Levinson AJ, Weaver B, Garside S, McGinn H, Norman GR. Virtual reality and brain anatomy: a randomised trial of e-learning instructional designs. Med Educ. 2007; 41(5):495-501.

10. Cook DA, Erwin PJ, Triola MM. Computerized virtual patients in health professions education: a systematic review and meta-analysis. Acad Med. 2010;85(10) 1589-1602.

11. Goldman J, Stebbins G, Fredericks D, Upchurch M. Experiencing Parkinson's Disease Psychosis via Virtual Reality Simulation: A Novel and Effective Educational Tool. P1. 011.

12. Yellowlees PM, Cook JN. Education about hallucinations using an internet virtual reality system: a qualitative survey. Acad Psych. 2006;30(6):534-539.

13. Konakondla S, Fong R, Schirmer CM. Simulation training in neurosurgery: advances in education and practice. Adv Med Educ Pract. 2017;8:465.

14. Mirchi N, Bissonnette V, Yilmaz R, Ledwos N, Winkler-Schwartz A, Del Maestro RF. The Virtual Operative Assistant: an explainable artificial intelligence tool for simulation-based training in surgery and medicine. PLoS One. 2020;15(2): e0229596.

15. Bailenson J. Protecting nonverbal data tracked in virtual reality. JAMA Pediatr. 2018; 172(10):905-906.

\section{Share Your Artistic Expressions in Neurology 'Visions'}

AAN members are urged to submit medically or scientifically related artistic images, such as photographs, photomicrographs, and paintings, to the "Visions" section of Neurology $y^{\bullet}$. These images are creative in nature, rather than the medically instructive images published in the NeuroImages section. The image or series of up to six images may be black and white or color and must fit into one published journal page. Accompanying description should be 100 words or less; the title should be a maximum of 96 characters including spaces and punctuation.

Please access the Author Center at NPub.org/authors for full submission information.

\section{Sign Up for the AAN's Axon Registry}

The AAN encourages its US members to show their interest in participating in the Axon Registry ${ }^{\circledR}$ by signing up today.

Use the Axon Registry to:

- Simplify reporting requirements under MACRA’s Quality Payment Program and avoid penalties while reducing your administrative burden

- Meet your MOC Part IV requirements and waive up to eight credits of Part II Self-Assessment

- Choose from 22 AAN neurology-specific quality measures that fit your practice

- Use data to understand your practice and identify where improvements can be made to patient care

- Manage your patients at a population level; look at a specific group of patients based on conditions, risk factors, demographics or outcome

- Demonstrate your value to payers when negotiating reimbursement

- Enjoy multi-year, fee-free access when you sign the agreements and integrate your EHR with the registry

Learn more at AAN.com/view/Axon and send your questions to registry@aan.com. 


\section{Neurology}

\section{Future of Neurology \& Technology: Virtual and Augmented Reality in Neurology and Neuroscience Education: Applications and Curricular Strategies}

Stefano Sandrone and Chad E. Carlson

Neurology 2021;97;740-744 Published Online before print June 29, 2021

DOI 10.1212/WNL.0000000000012413

This information is current as of June 29, 2021

\section{Updated Information \& Services}

References

Citations

Subspecialty Collections

Permissions \& Licensing

Reprints including high resolution figures, can be found at: http://n.neurology.org/content/97/15/740.full

This article cites 12 articles, 1 of which you can access for free at: http://n.neurology.org/content/97/15/740.full\#ref-list-1

This article has been cited by 1 HighWire-hosted articles: http://n.neurology.org/content/97/15/740.full\#\#otherarticles

This article, along with others on similar topics, appears in the following collection(s):

\section{All Education}

http://n.neurology.org/cgi/collection/all_education

Computer use in education

http://n.neurology.org/cgi/collection/computer_use_in_education

Methods of education

http://n.neurology.org/cgi/collection/methods_of_education

Other Education

http://n.neurology.org/cgi/collection/other_education

Information about reproducing this article in parts (figures,tables) or in its entirety can be found online at:

http://www.neurology.org/about/about_the_journal\#permissions

Information about ordering reprints can be found online:

http://n.neurology.org/subscribers/advertise

Neurology ${ }^{\circledR}$ is the official journal of the American Academy of Neurology. Published continuously since 1951, it is now a weekly with 48 issues per year. Copyright () 2021 American Academy of Neurology. All rights reserved. Print ISSN: 0028-3878. Online ISSN: 1526-632X.

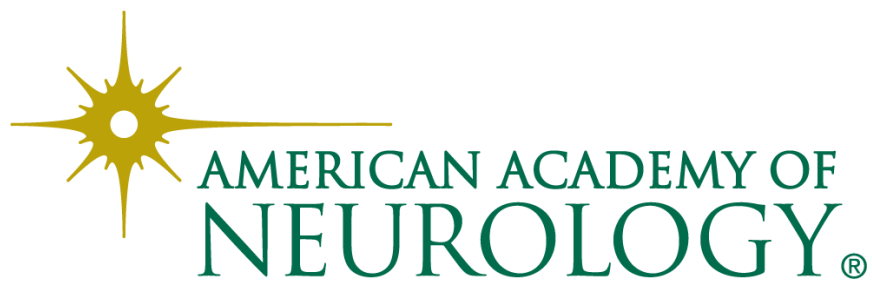

